market alongside the EEC. Japan's deforestation activities will now come under intense scrutiny from conservation lobbyists and from other consumer nations, which face growing domestic pressures to curb their own part in forest destruction.

The International Tropical Timber Organization members are:

\section{Producers}

\author{
Africa \\ Cameroun, Congo, Côte d'Ivoire, Gabon, Ghana, \\ Greece \\ Asia
}

India, Indonesia, Malaysia, Papua New Guinea, Philip-

pines, Thailand

Latin America

Bolivia, Brazil, Ecuador, Honduras, Peru, Trinidad \&

Tobago

\section{CONSUMERS}

EEC

Belgium/Luxembourg, Denmark, France, Germany (Fed. Rep.), Liberia, Ireland, Italy, Netherlands, Spain, United Kingdom; Others

Austria, Canada, China, Egypt, Finland, Japan, Korea (Rep.), Norway, Sweden, Switzerland, USA, USSR.

\author{
CHRISTOPHER ROSE \\ WWF International \\ World Conservation Centre \\ Avenue du Mont-Blanc \\ 1196 Gland \\ Switzerland.
}

\title{
Important Aspect-ASEP
}

The Asian Society for Environmental Protection (ASEP) was established as a result of a meeting at Augsburg, Federal Republic of Germany, on 28 September 1984, by the participants of the Workshop/Study-tour on Asian-Bavarian Cooperation in Environmental Management, which was sponsored by the Federal Ministry of Economic Cooperation (BMZ) and the Bavarian Ministry of Economic Affairs and Transport. It was organized and established by the Carl Duisberg Gesellschaft e.V. (CDG) in close cooperation with the Office of the German Programme Coordinator, Asian Institute of Technology (AIT) in Bangkok, and the Landesamt fuer Umweltschutz in Munich.

The main task of ASEP is to coordinate environmental management through national and international cooperation by promoting exchange of professional experience, making recommendations, and satisfying some relevant training programme needs of the Asian countries. Furthermore, it aims at facilitating exchange of information and intra-regional cooperation programmes, and in promoting closer links and bilateral cooperation among its members. Since the first was published in June 1985, there have been four different issues of the ASEP Newsletter, which have published the latest information on various environmental activities of experts attached to the Society, and also responded to the growing need of stimulating public awareness regarding significant actions and activities that are pertinent to sustainable development.

During the first meeting, in September 1984, the ASEP Secretariat was formed. It is composed of a Chairman, a Secretary-General, Treasurer, and an Adviser-to function administratively for the purpose of achieving the objectives of the Society. Likewise, a national coordinator for each member country was chosen to motivate and mobilize the active participation of the national members. Today, the correspondence address of the Secretariat is CDGSEAPO, Asian Institute of Technology, G.P.O. Box 2754, Bangkok 10501, Thailand.

ASEP started with 23 members from 7 countries and has already increased to 78 members from 18 countries. Its membership is open to professionals whose work or field of interest is related to any aspect of environmental protection.

EDDIE K.S. Hum, Secretary-General Asian Society for Environmental Protection CDG-SEAPO

Asian Institute of Technology

GPO BOX 2754

Bangkok 10501

Thailand.

\section{Towards a World Ecoregions Map?}

One can only agree with the proposal 'to create a map showing the world subdivided into macroecosystem regions' (Bailey \& Hogg, 1986). Nevertheless, it is also essential to recognize that the 'world' of Bailey \& Hogg is scarely a quarter of our globe - the part that is high-and-dry terrestrial. A terrestrial macroecosystem subdivision would be quite useful in itself, but this would almost surely place a large part of our planet-namely the Africa-and-a-halfsized 'coastal zone' - in a completely erroneous context. I attempted to point this out in a recent Guest Editorial (Ray, 1986).

Bailey \& Hogg correctly make the point that 'the boundaries of ecoregions are determined to a considerable extent by climatic factors.' This is, in large part, the point also made by Hayden, Ray \& Dolan (1984) in classifying coastal and marine environments. Indeed, it might be justifiable to combine this coastal-marine scheme with such an attempt as that of Udvardy (1975), in a first approximation of a truly 'world' classification.

There is a clear and urgent need to develop a global classification for all the purposes mentioned by Bailey \& Hogg (1986). Equally, it will be mandatory to develop compatible methods and analogous terms for terrestrial, coastal, and marine, systems. However, a call for a "world ecoregions map' that is solely terrestrial cannot be seriously entertained.

\section{REFERENCES}

Balley, R.G. \& HogG, H.C. (1986). A world ecoregions map for resource reporting. Environmental Conservation, 13(3), pp. 195-202, map.

Hayden, B.P., Ray, G.C. \& Dolan, R. (1984). Classification of coastal and marine environments. Environmental Conservation, 11(3), pp. 199-207, 6 maps.

RAY, G.C. (1986). Conservation concepts for the seas and coasts. Environmental Conservation, 13(2), pp. 95-6.

UDVARDY, M.D.F. (1975). A Classification of the Biogeographical Provinces of the World. International Union for Conservation of Nature and Natural Resources Occasional Paper 18. Morges, Switzerland: 48 pp., illustr.

G. Carleton Ray, Research Professor Department of Environmental Sciences Clark Hall

University of Virginia

Charlottesville

Virginia 22903, USA. 